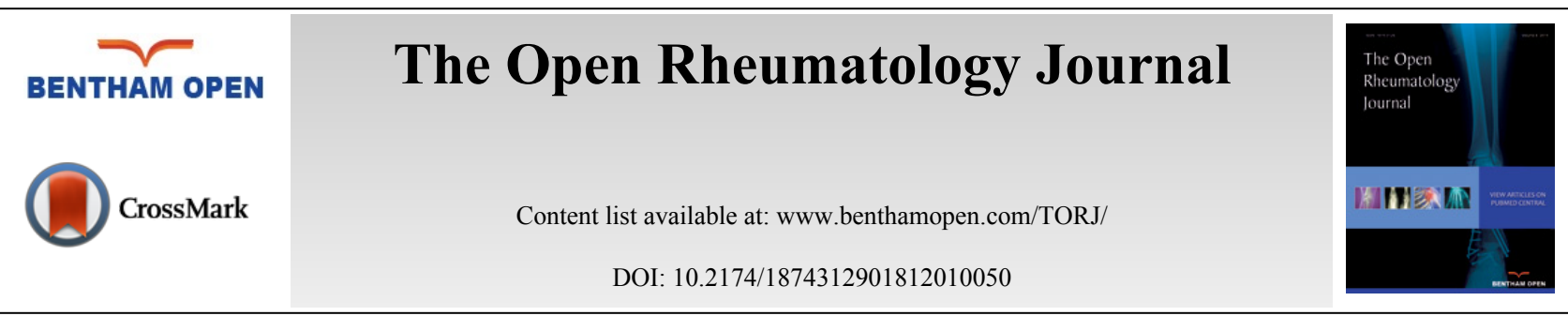

RESEARCH ARTICLE

\title{
The Prevalence of Osteopenia and Osteoporosis Among Malaysian Type 2 Diabetic Patients Using Quantitative Ultrasound Densitometer
}

\author{
Shaymaa Abdalwahed Abdulameer ${ }^{1, *}$, Mohanad Naji Sahib ${ }^{1}$ and Syed Azhar Syed Sulaiman ${ }^{2}$ \\ ${ }^{I}$ Faculty of Pharmacy, Al-Rafidain University College, Palestine Street, 10052, Baghdad, Iraq \\ ${ }^{2}$ School of Pharmaceutical Sciences, Universiti Sains Malaysia, Minden, 11800, Penang, Malaysia
}

Received: December 30, 2017

Revised: March 6, 2018

Accepted: March 30, 2018

\author{
Abstract: \\ Background: \\ Type 2 Diabetes Mellitus (T2DM) and osteoporosis are both chronic conditions and the relationship between them is complex.
}

Objective:

The aims of this study were to assess the prevalence of Low Bone Mineral density (LBMD, i.e., osteopenia and osteoporosis), as well as, the difference and associations between Quantitative Ultrasound Scan (QUS) parameters with socio-demographic data and clinical related data among T2DM in Penang, Malaysia.

\section{Method:}

An observational, cross-sectional study with a convenient sample of 450 T2DM patients were recruited from the outpatient diabetes clinic at Hospital Pulau Pinang (HPP) to measure Bone Mineral Density (BMD) at the heel bone using QUS. In addition, a selfreported structured questionnaire about the socio-demographic data and osteoporosis risk factors were collected. Moreover, the study included the retrospective collection of clinical data from patients' medical records.

\section{Results:}

The mean value of T-score for normal BMD, osteopenic and osteoporotic patients' were (-0.41 \pm 0.44$),(-1.65 \pm 0.39)$ and $(-2.76 \pm 0.27)$, respectively. According to QUS measurements, more than three quarters of T2DM patients (82\%) were at high risk of abnormal BMD. The results showed that QUS scores were significantly associated with age, gender, menopausal duration, educational level and diabetic related data. Moreover, the QUS parameters and T-scores demonstrated significant negative correlation with age, menopausal duration, diabetic duration and glycaemic control, as well as, a positive correlation with body mass index and waist to hip ratio. The current study revealed that none of the cardiovascular disease risk factors appear to influence the prevalence of low BMD among T2DM Malaysian patients.

\section{Conclusion:}

The study findings revealed that the assessment of T2DM patients' bone health and related factor are essential and future educational programs are crucial to improve osteoporosis management.

Keywords: Diabetes, Malaysia, Osteopenia, Osteoporosis, Prevalence, Quantitative ultrasound.

\section{INTRODUCTION}

Osteoporosis condition is recognised as a "silent global problem", which is characterised by a reduction in the bone

* Address correspondence to this author at the Faculty of Pharmacy, Al-Rafidain University College, Palestine Street, 10052, Baghdad, Iraq; Tel: 00964-07500271748; E-mail: xbm2004@yahoo.com 
mass and micro-architectural deterioration of bone tissue, leading to impaired skeletal strength with a consequent increase in bone fragility and susceptibility to fracture $[1,2]$. However, osteoporosis does not have a dramatic clinical presentation and frequently remain undiagnosed until there is a fracture or a screening test is conducted [3, 4]. Moreover, the growth of the aged population is rapidly increasing with increased lifespans of the population due to medical improvements in the developed as well as the developing world, which contributes to a significant increase in the prevalence of osteoporosis with a consequently increased number of fractures [5, 6]. Thus, osteoporosis imposes a significant and heavy burden on the individual and healthcare system [7]. The osteoporotic condition negatively and significantly impacts morbidity as well as can lead to chronic pain, deformity, impair mobility and increased risk of death [8]. In addition, persons with high cumulative rate of fractures were often disabled with decreased functional capacity and poor quality of life $[9,10]$, as well as, become dependent on others $[11,12]$.

Bone Mineral Density (BMD) is an important factor linked to bone health and fracture risk. It is well known that BMD in the United States and European Caucasian groups is higher than that in the Asian populations [13 - 15]. However, with the rise in Asian population, it is predicted that Asian countries will be progressively increasing in the incidence of fractures and more than half of all fractures around the world will occur in Asia by 2050 [16]. Many studies have indicated that Quantitative Ultrasound Scan (QUS) has emerged as a new and adequate tool that offers an alternative or adjunct to Dual energy X-ray Absorptiometry (DXA) for screening and assessing the peripheral skeleton status. Thus, QUS accurately predicts the relative risk of all fracture risks similar to that from DXA measurements of the hip and spine $[17,18]$. Moreover, there were many studies that had shown that the T-score resulting from the QUS method were correlated with the T-scores resulting from the DXA method [19, 20]. Furthermore, QUS parameters reflect BMD, as well as, other mechanical characteristics of the bone, such as elasticity, microarchitecture and strength $[21,22]$. In addition, QUS can discriminate between individuals with a low risk and high risk of having abnormal BMD in the clinical setting [23, 24]. According to the recommendations of the International Society for Clinical Densitometry, the calcaneus (heel) is the only ideal validated anatomic site for bone mass screening using QUS method because it is weight-bearing and trabecular rich [25, 26].

On the other hand, Type 2 Diabetes Mellitus (T2DM) and osteoporosis are both chronic conditions; the relationship between them is complex. Clinical data uniformly support that bone formation and bone micro-architectural integrity are altered in diabetic patients [27, 28]. Moreover, glucose metabolism impairment has a number of detrimental effects on bone remodeling in terms of reduced bone mass [29, 30] and an increased risk of fractures [31]. In view of the current high prevalence of T2DM (14.90\%) [32] and osteoporosis (24.10\%) [33] in Malaysia, there is a great interest in studying the possible prevalence of osteoporotic status (normal BMD, osteopenia and osteoporosis) in T2DM patients. To date, there has been no clinical study exploring the prevalence of osteoporotic conditions in Malaysian T2DM patients. Therefore, the present study aimed to assess the prevalence of Low Bone Mineral Density (LBMD, i.e., osteopenia and osteoporosis) in T2DM, as well as, the difference and associations between QUS parameters with sociodemographic data and clinical related data.

\section{MATERIALS AND METHODS}

\subsection{Study design}

An observational, cross-sectional study with a self-reported structured questionnaire about the socio-demographic data and osteoporosis risk factor was used for this study. In addition, the study included the retrospective collection of clinical data from patients' medical records. The study population consisted of diabetes outpatients attending the Diabetes Outpatient Clinic of Hospital Palua Pinang (HPP), from $1^{\text {st }}$ August 2011 to $30^{\text {th }}$ February 2012. The study population was recruited using a convenient sampling method. The inclusion criteria in the present study were: patients diagnosed with T2DM (depending on the medical record) at least two years before inclusion in the study, age $\geq 18$ years old and able to read and write with no speech or hearing problems.

\subsection{Sample Size}

The following Cochran formula was used to calculate the required sample size for this study [34]:

$$
n=\frac{Z^{2} \mathrm{P}(1-\mathrm{P})}{d^{2}}
$$

Where $\mathrm{n}=$ sample size, $\mathrm{Z}=\mathrm{Z}$ statistic for a level of confidence (the value of $Z$ is set at 2.58 with a confidence of 
about $99 \%$ ), $\mathrm{P}=$ expected prevalence or proportion (the T2DM prevalence in Malaysia is $14.9 \%$ according to the third National Health and Morbidity Survey (NHMS III) [35, 32]; therefore, $\mathrm{P}$ is equal to 0.149), and $\mathrm{d}=$ precision (in proportion of one; if $5 \%, \mathrm{~d}=0.05)$, because it is appropriate to have a precision of $5 \%$ if the prevalence of the disease is estimated to be between $10 \%$ and $90 \%$. Using an accepted margin of error of $5 \%$ and a $99 \%$ confidence interval, the required sample size was calculated to be 338 patients. With the inclusion of an additional $40 \%$ (to cover study dropouts) to minimise erroneous results and increase the study reliability, the target sample size was increased to 474 patients.

\subsection{Bone Mass Measurements}

The skeletal health status was evaluated using Quantitative Ultrasound Scan (QUS) measurements to determine the prevalence of LBMD at the heel bone (calcaneus) and these measurements was carried out by the SONOST 3000 clinical bone densitometer (OsteoSys Co., Ltd, Seoul, Korea). Quality assurance tests were run on a daily basis according to the manufacturer's protocol with the standard phantom before each data collection session to ensure the stability of QUS measurements. The QUS measurements were obtained from the right calcaneus for all patients in a room temperature controlled environment, as suggested by the manufacturer, and the measurements were conducted by the same investigator throughout the studies.

The QUS measures two basic parameters, Broadband Ultrasound Attenuation (BUA) and the Speed Of Sound (SOS), in addition to the T-score, which is comparable to that obtained by DXA. The BUA, expressed in decibels/megahertz $(\mathrm{dB} / \mathrm{MHz})$, is concerned with the structural features of bones and is a measurement of different attenuations of the ultrasound waves transmitted through the calcaneus [36, 37]. In contrast, SOS, expressed in meters/second $(\mathrm{m} / \mathrm{s})$, is concerned with bone strength, fragility and elasticity, which translates the time necessary for ultrasound to travel through the calcaneus [38, 26, 39].

Moreover, Stiffness Index (SI) and estimate Bone Mineral Density (eBMD) parameters were generated from both BUA and SOS. The SI and eBMD, expressed in percent $(\%)$ and $\mathrm{g} / \mathrm{cm}^{2}$, respectively, are variables derived from a linear combination of BUA and SOS and calculated according to the following equations [40, 41]:

$$
\begin{aligned}
& \mathrm{SI}=((0.67 \times \mathrm{BUA})+(0.28 \times \mathrm{SOS})-420) \\
& \mathrm{eBMD}=(0.0025926 \times(\mathrm{BUA}+\mathrm{SOS})-3.687)
\end{aligned}
$$

Some studies have shown that SI has the best correlation with BMD (measured by DXA) and fracture risk [38, 42, 43]. The QUS-score measurements were categorised into three groups (normal BMD, osteopenia and osteoporosis) according to the World Health Organization (WHO) criteria which have been standardised by the manufacturer for Asian population. Osteoporosis, osteopenia and normal conditions are identified as (T-score $\leq-2.5$ SD), (T-score between -1.0 and -2.5 ) and (T-score $>-1.0$ ) below the healthy young adult reference mean, respectively [44]. In addition, osteoporotic conditions of the T2DM patients were stratified into two groups: a normal group (low risk for abnormal BMD with T-score $>-1$ ) and an osteoporotic condition group (high risk for abnormal BMD with T-score $\leq-1$ (i.e. osteopenia and osteoporosis) [45].

\subsection{Ethical Considerations}

Before the initiation of this study, all aspects of the study protocol were approved by the Clinical Research Centre (CRC) of HPP and the Medical Research Ethics Committee (MREC) of the Ministry of Health, Malaysia (NMRR-11-28-8209). All subjects were provided with a written informed consent form prior to participation in this study. All personal information collected was considered confidential.

\subsection{Statistical Analysis}

Data obtained from the interviews and medical records were checked to ensure completeness. All statistical analyses were performed using Predictive Analytics Software (PASW) version 19.0 and the level of statistical significance was set less than $0.05(P<0.05)$. Descriptive statistics representing mean \pm standard deviations $(\mathrm{M} \pm \mathrm{SD})$, percentages $(\%)$, ranges, and 95\% Confidence Intervals (CI) were used to describe demographic and disease characteristics of the patients. Percentages and frequencies were used for categorical variables and the associations between categorical variables were examined using chi square $\left(\chi^{2}\right)$ test. Continuous normally distributed variables were compared using the One Way Analysis Of Variance (ANOVA) test, Analysis Of Covariance (ANCOVA) and independent student t-test 
when appropriate. Post hoc analysis using Hochberg's GT2 was conducted when necessary. The Hochberg's GT2 test was used because of the unequal sample size among the groups [46]. However, the Kruskal Wallis test was used for continuous non-normal distribution data. Spearman and Pearson correlation were used to measure the correlation between continuous variables when appropriate.

\section{RESULTS}

\subsection{Overall Response Rate}

A total of 500 patients were recruited from the outpatient diabetes clinic. Out of the 500 patients approached, 50 patients were excluded due to a lack of some clinical data $(n=31)$ or incomplete responses from the patients $(n=19)$. The final convenience sample of 450 patients with T2DM was included in the analysis of this study, which was considered to be acceptable with a margin of error $( \pm 5 \%)$ and $99 \%$ confidence interval [47].

\subsection{Bone Health Status and Prevalence of Osteoporotic Conditions}

All T2DM patients were screened for BMD using QUS measurement. The mean value of T-score for the total sample $(\mathrm{N}=450)$ was $(-1.67 \pm 0.83)$ ((median: -1.65) (range: -3.4 to 1.2$)(\mathrm{CI} 95 \%$ : -1.75 to -1.59$))$. The mean value of Tscore for normal BMD, osteopenic and osteoporotic patients' were $(-0.41 \pm 0.44),(-1.65 \pm 0.39)$ and $(-2.76 \pm 0.27)$, respectively. In addition, the mean values of the QUS parameters as following: BUA, SOS, SI and eBMD were 67.09 $\pm 15.40 \mathrm{~dB} / \mathrm{MHz}, 1514.37 \pm 14.26 \mathrm{~m} / \mathrm{s}, 48.98 \pm 13.53 \%$ and $0.41 \pm 0.07 \mathrm{gm} / \mathrm{cm}^{2}$, respectively. According to QUS measurements, the prevalence of normal BMD was $18 \%(n=81)$, while the prevalence of osteopenia and osteoporosis were considered as $59.8 \%(n=269)$ and $22.2 \%(n=100)$, respectively.

\subsection{Bone Health Status and Socio-Demographic Data}

The QUS measurements identified 369 patients (82\%) out of 450 with high risk of abnormal BMD. The sociodemographic and osteoporotic conditions are presented in Table 1. The results showed a higher proportion of males with a low risk of abnormal BMD (67.90\%) and a higher proportion of females with a high risk of abnormal BMD $(52.30 \%)(P<0.05)$. Moreover, there were significant differences in QUS-score (normal BMD, osteopenia and osteoporosis) with age, menopausal duration, anthropometric indicators (BMI, WHR) and educational level $(P<0.05)$.

Table 1. The main patient characteristics regarding the prevalence of osteoporosis and osteopenia among type 2 diabetic patients $(\mathbf{N}=\mathbf{4 5 0})$.

\begin{tabular}{|c|c|c|c|c|c|}
\hline \multirow{4}{*}{ Variable } & \multirow{4}{*}{$\begin{array}{c}\text { Total Sample (M } \pm \text { SD) or } \\
\text { N (\%) }\end{array}$} & \multicolumn{3}{|c|}{ QUS score, $\mathbf{N}(\%)$} & \multirow{4}{*}{$P$ value } \\
\hline & & \multirow{2}{*}{\begin{tabular}{|c|} 
Normal BMD \\
Normal \\
\end{tabular}} & \multicolumn{2}{|c|}{ LBMD } & \\
\hline & & & Osteopenia & Osteoporosis & \\
\hline & & $81(18.0 \%)$ & $269(59.8 \%)$ & $100(22.2 \%)$ & \\
\hline Age (years) & $62.67 \pm 9.24$ & $60.78 \pm 9.88$ & $62.68 \pm 9.19$ & $64.19 \pm 8.62$ & $0.047^{\mathrm{a}^{*}}$ \\
\hline Menopausal age (years) $(\mathrm{N}=194)$ & $48.81 \pm 1.83$ & $49.50 \pm 2.19$ & $48.88 \pm 1.71$ & $48.30 \pm 1.88$ & $0.019^{b^{*}}$ \\
\hline Menopausal duration (years) $(\mathrm{N}=194)$ & $15.16 \pm 7.98$ & $10.32 \pm 8.59$ & $15.37 \pm 7.80$ & $16.93 \pm 7.42$ & $0.003^{b^{*}}$ \\
\hline BMI, $\mathrm{kg} / \mathrm{m}^{2}$ & $26.36 \pm 4.39$ & $29.33 \pm 4.99$ & $25.64 \pm 3.83$ & $25.88 \pm 4.34$ & $0.000^{b^{*}}$ \\
\hline Waist to hip ratio & $0.911 \pm 0.06$ & $0.93 \pm 0.063$ & $0.91 \pm 0.06$ & $0.91 \pm 0.06$ & $0.006^{\mathrm{a}^{*}}$ \\
\hline Gender & & & & & $0.004^{\mathrm{c}^{*}}$ \\
\hline Male & $231(51.3)$ & $55(23.8)$ & $126(54.5)$ & $50(21.6)$ & \\
\hline Female & $219(48.7)$ & $26(11.9)$ & $143(65.3)$ & $50(22.8)$ & \\
\hline Race & & & & & $0.572^{\mathrm{c}}$ \\
\hline Malay & $127(28.2)$ & $27(21.3)$ & $73(57.5)$ & $27(21.3)$ & \\
\hline Chinese & $204(45.3)$ & $30(14.7)$ & $128(62.7)$ & $46(22.5)$ & \\
\hline Indian & $119(26.4)$ & $24(20.2)$ & $68(57.1)$ & $27(22.7)$ & \\
\hline Educational levels & & & & & $0.015^{\mathrm{c}^{*}}$ \\
\hline$<12$ years & $285(63.3)$ & $42(14.7)$ & $184(64.6)$ & $59(20.7)$ & \\
\hline$\geq 12$ years & $165(36.7)$ & $39(23.6)$ & $85(51.5)$ & $41(24.8)$ & \\
\hline Monthly income & & & & & $0.868^{\mathrm{c}}$ \\
\hline Less than RM 2000 & $330(73.3)$ & $61(18.5)$ & $195(59.1)$ & $74(22.4)$ & \\
\hline More than RM 2000 & $120(26.7)$ & $20(16.7)$ & $74(61.7)$ & $26(21.7)$ & \\
\hline
\end{tabular}


(Table 1) contd.....

\begin{tabular}{|c|c|c|c|c|c|}
\hline \multirow{4}{*}{ Variable } & \multirow{4}{*}{$\begin{array}{c}\text { Total Sample }(\mathrm{M} \pm \mathrm{SD}) \text { or } \\
\text { N }(\%)\end{array}$} & \multicolumn{3}{|c|}{ QUS score, N (\%) } & \multirow{4}{*}{$P$ value } \\
\hline & & \multirow{3}{*}{\begin{tabular}{|c|} 
Normal BMD \\
Normal \\
$\mathbf{8 1}(18.0 \%)$ \\
\end{tabular}} & \multicolumn{2}{|c|}{ LBMD } & \\
\hline & & & Osteopenia & Osteoporosis & \\
\hline & & & $269(59.8 \%)$ & $100(22.2 \%)$ & \\
\hline Menopausal status $(\mathrm{N}=\mathbf{2 1 9})$ & & & & & $0.602^{c}$ \\
\hline Premenopausal & $25(11.4)$ & $4(16.0)$ & $17(68.0)$ & $4(16.0)$ & \\
\hline Postmenopausal & $194(88.6)$ & $22(11.3)$ & $126(64.9)$ & $46(23.7)$ & \\
\hline Employment status & & & & & $0.527^{c}$ \\
\hline Working & $192(42.7)$ & $30(15.6)$ & $118(61.5)$ & $44(22.9)$ & \\
\hline Not working & $258(57.3)$ & $51(19.8)$ & $151(58.5)$ & $56(21.7)$ & \\
\hline Living place & & & & & $0.074^{\mathrm{c}}$ \\
\hline Rural & $90(20)$ & $10(11.1)$ & $54(60.0)$ & $26(28.9)$ & \\
\hline Urban & $360(80)$ & $71(19.7)$ & $215(59.7)$ & $74(20.6)$ & \\
\hline Family history of osteoporosis & & & & & $0.451^{\mathrm{c}}$ \\
\hline No & $392(87.1)$ & $73(18.6)$ & $230(58.7)$ & $89(22.7)$ & \\
\hline Yes & $58(12.9)$ & $8(13.8)$ & $39(67.2)$ & $11(19.0)$ & \\
\hline Family history of Fracture & & & & & $0.258^{\mathrm{c}}$ \\
\hline No & $359(79.8)$ & $70(19.5)$ & $211(58.8)$ & $78(21.7)$ & \\
\hline Yes & $91(20.2)$ & $11(12.1)$ & $58(63.7)$ & $22(24.2)$ & \\
\hline Smoking habit & & & & & $0.853^{\mathrm{c}}$ \\
\hline Not smoking & $318(70.7)$ & $59(18.6)$ & $190(59.7)$ & $69(21.7)$ & \\
\hline Smoking & $132(29.3)$ & $22(16.7)$ & $79(59.8)$ & $31(23.5)$ & \\
\hline Alcohol habit & & & & & $0.122^{\mathrm{c}}$ \\
\hline Non alcoholic & $356(79.1)$ & $70(19.7)$ & $212(59.6)$ & $74(20.8)$ & \\
\hline Alcoholic & $94(20.9)$ & 11(11.7) & $57(60.6)$ & $26(27.7)$ & \\
\hline
\end{tabular}

${ }^{a}$ Continuous data are presented as mean \pm standard deviation $(\mathrm{M} \pm \mathrm{SD}$ ) and $P$ values were derived from one-way analysis of variance (for continuous variables normal distributed),

${ }^{\mathrm{b}}$ Continuous data are presented as mean \pm standard deviation $(\mathrm{M} \pm \mathrm{SD})$ and $P$ values were derived from Kruskal Wallis test (for continuous variables not normal distributed),

${ }^{\mathrm{c}}$ Categorical variables, expressed as frequency (percentage, $\%$ ) of sample and $P$ values were derived from the Chi-square test, ${ }^{*} p<0.05$.

QUS, quantitative ultrasound; BMD, bone mineral density; LBMD, low bone mineral density; RM, Ringgit Malaysia.

There was a significant difference in QUS-score with age $(P<0.05)$. Post hoc analysis (Hochberg's GT2) showed that the osteoporotic and normal groups were significantly different with age $(P<0.05)$, while there were insignificant differences between the osteopenia group and both osteoporosis and normal groups $(P>0.05)$ regarding mean age. However, the results showed that the mean age of the osteoporosis group ( $64.19 \pm 8.62$ years) was higher than that of both the osteopenic (62.68 \pm 9.19 years) and normal (60.78 \pm 9.88 years) groups. In addition, there was a significant difference in QUS-score when stratified according to menopausal duration $(P<0.05)$. The mean menopausal duration of

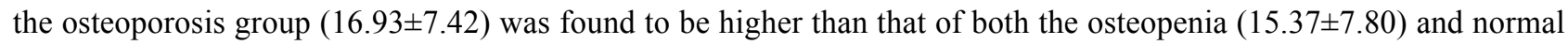
(10.32 \pm 8.59$)$ groups.

In short, the anthropometric measurement values for the osteopenia and osteoporosis groups were significantly lower than for the normal group $(P<0.05)$. In addition, higher proportion of osteopenia $(68.40 \%)$ and normal BMD $(48.10 \%)$ among those with an educational level less than 12 years than in those with more than 12 years, respectively $(P<0.05)$; however, there was an insignificant difference in the proportion between educational levels with osteoporosis group $(P>0.05)$. Finally, the results showed insignificant associations between the osteoporotic status (normal BMD, osteopenia and osteoporosis) with race, income, menopausal status, living place, employment status, family history of osteoporosis, family history of fracture, alcohol and smoking habits $(P>0.05)$, as shown in Table $\mathbf{1}$.

Furthermore, the results showed significant negative correlations between T-score and QUS parameters with age in years, menopause duration $(P<0.05)$ (Table 2). On the other hand, positive correlations between T-score and QUS parameters with BMI and WHR $(P<0.05)$ were found.

\subsection{Quantitative Ultrasound Parameters Measurements' with Age and Gender}

The QUS parameters of the calcaneus stratified by age decade and gender are presented in Table $\mathbf{3}$. The present study showed that the parameters of QUS (BUA, SOS, eBMD, SI) gradually decreased in both sexes with increasing 
age. Men presented higher values for all parameters in comparison to women. In addition, higher values for all parameters, in both sexes, were detected in younger age groups (less than 45 years). There were significant effects of age on the levels of SOS, BUA, SI and eBMD after controlling for the effects of gender and race $(P<0.05)$. In addition, the covariate race was insignificantly related to all parameters $(P>0.05)$. Furthermore, the covariate gender was significantly related to all parameters except $\mathrm{SOS}(P>0.05)$.

Table 2. Correlation between T-score and quantitative ultrasound scan parameter values with socio-demographic data $(\mathrm{N}=450)$.

\begin{tabular}{|c|c|c|c|c|c|}
\hline Variables & T-score & BUA & SOS & SI & eBMD \\
\hline Age (years), $r$ & $-0.173 * *$ & $-0.170 * *$ & $-0.156^{* *}$ & $-0.176^{* *}$ & $-0.175 * *$ \\
\hline Menopausal age (years), $r_{s}$ & 0.090 & 0.135 & 0.043 & 0.124 & 0.108 \\
\hline Menopausal duration (years), $r_{s}$ & $-0.207 * *$ & $-0.194 * *$ & $-0.192 * *$ & $-0.212 * *$ & $-0.208 * *$ \\
\hline $\operatorname{BMI}\left(\mathrm{kg} / \mathrm{m}^{2}\right), r_{s}$ & $0.188^{* *}$ & $0.200 * *$ & $0.159 * *$ & $0.201 * *$ & $0.196^{* *}$ \\
\hline Waist to hip ratio, $r$ & $0.099 *$ & $0.139 * *$ & 0.069 & $0.126^{* *}$ & $0.113 *$ \\
\hline
\end{tabular}

BUA, broadband ultrasound attenuation; SOS, speed of the sound; SI, stiffness index; eBMD, estimated bone mineral density; BMI, body mass index. $* \mathrm{P}<0.05, * * \mathrm{P}<0.01$

Table 3. The quantitative ultrasound scan parameters of the calcaneus stratified by age groups and gender $(\mathrm{N}=450)$.

\begin{tabular}{|c|c|c|c|c|c|c|c|c|}
\hline \multirow{3}{*}{$\begin{array}{l}\text { Variables } \\
\text { Age group }\end{array}$} & \multicolumn{8}{|c|}{ Gender } \\
\hline & \multicolumn{4}{|c|}{ Female } & \multicolumn{4}{|c|}{ Male } \\
\hline & BUA (dB/MHz) & $\begin{array}{l}\text { SOS } \\
(\mathrm{m} / \mathbf{s})\end{array}$ & SI \% & $\begin{array}{l}\text { eBMD } \\
\left(\mathrm{g} / \mathrm{cm}^{2}\right)\end{array}$ & $\begin{array}{c}\text { BUA } \\
(\mathrm{dB} / \mathrm{MHz})\end{array}$ & $\begin{array}{l}\text { SOS } \\
(\mathrm{m} / \mathbf{s})\end{array}$ & SI \% & $\begin{array}{l}\text { eBMD } \\
\left(g / \mathrm{cm}^{2}\right)\end{array}$ \\
\hline$>45$ years & $78.96 \pm 15.50$ & $1516.84 \pm 15.57$ & $57.62 \pm 14.04$ & $0.45 \pm 0.08$ & $77.35 \pm 21.81$ & $1520.10 \pm 20.83$ & $57.45 \pm 19.78$ & $0.45 \pm 0.11$ \\
\hline $45-54$ years & $70.92 \pm 14.69$ & $1519.98 \pm 14.82$ & $53.11 \pm 13.34$ & $0.43 \pm 0.07$ & $70.68 \pm 14.81$ & $1514.99 \pm 14.69$ & $51.56 \pm 13.09$ & $0.42 \pm 0.07$ \\
\hline 55-64 years & $62.13 \pm 14.05$ & $1511.87 \pm 12.79$ & $44.95 \pm 12.37$ & $0.39 \pm 0.07$ & $70.18 \pm 15.92$ & $1516.58 \pm 14.96$ & $51.66 \pm 14.03$ & $0.43 \pm 0.07$ \\
\hline$\geq 65$ years & $62.14 \pm 12.48$ & $1510.94 \pm 12.74$ & $44.69 \pm 10.92$ & $0.39 \pm 0.06$ & $68.32 \pm 16.53$ & $1514.21 \pm 14.44$ & $49.76 \pm 14.38$ & $0.41 \pm 0.08$ \\
\hline Total & $64.52 \pm 14.22$ & $1513.35 \pm 13.69$ & $46.96 \pm 12.59$ & $0.40 \pm 0.07$ & $69.54 \pm 16.11$ & $1515.35 \pm 14.74$ & $50.89 \pm 14.12$ & $0.42 \pm 0.07$ \\
\hline
\end{tabular}

BUA, broadband ultrasound attenuation; SOS, speed of sound; SI, stiffness index; eBMD, estimated bone mineral density.

Values are shown as mean \pm standard deviation $(\mathrm{M} \pm \mathrm{SD})$.

\subsection{Bone Health Status with Clinical Related Data}

In this study, significant associations between QUS-score and glycaemic control (HbAlc) and diabetes duration were found $(P<0.05)$, respectively. The results showed a higher proportion of osteoporosis $(83 \%)$ in poor glycaemic control $(\mathrm{HbA} 1 \mathrm{c} \geq 6.5)$ and higher proportion of normal BMD (34.60\%) among good glycaemic control patients $(\mathrm{HbA} 1 \mathrm{c}<6.5)$, respectively $(\mathrm{P}<0.05)$; however, there was an insignificant difference in proportion between glycaemic control with osteopenia group $(\mathrm{P}>0.05)$. Moreover, the results showed significantly a higher proportion of osteopenia $(34.20 \%)$ and osteoporosis $(43 \%)$ in the group with a diabetes duration of more than 10 years and a higher proportion of normal BMD $(81.50 \%)$ in the group with a diabetes duration of less than 10 years $(\mathrm{P}<0.05)$. In addition, there were insignificant association between QUS-score and the other diabetes-related variables $(P>0.05)$ as shown in Table 4. Furthermore, insignificant associations between QUS-score with lipid and blood pressure profiles variables (data not shown) $(P>0.05)$.

Table 4. Relationships between quantitative ultrasound scan score and diabetes-related variables $(\mathrm{N}=\mathbf{4 5 0})$.

\begin{tabular}{|c|c|c|c|c|c|}
\hline \multirow{2}{*}{ Variable } & \multirow{2}{*}{ Total Sample (N=450) } & \multicolumn{3}{|c|}{ QUS Score, N (\%) } & \multirow{2}{*}{ LBMD } \\
\cline { 3 - 7 } & $\mathbf{N}(\%)$ & Normal BMD & \multicolumn{3}{|c|}{ P value } \\
\cline { 3 - 7 } & & Normal & Osteopenia & Osteoporosis \\
\cline { 3 - 7 } & & $\mathbf{8 1 ( 1 8 . 0 \% )}$ & $\mathbf{2 6 9 ( 5 9 . 8 \% )}$ & $\mathbf{1 0 0 ( 2 2 . 2 \% )}$ & \\
\hline Diabetes Duration (years) & & & & & $0.002 *$ \\
\hline Less than 10 years & $300(66.7 \%)$ & $66(22.0)$ & $177(59.0)$ & $57(19.0)$ & \\
\hline More than 10 years & $150(33.3)$ & $15(10.0)$ & $92(61.3)$ & $43(28.7)$ & \\
\hline Diabetic complication (DC) & & & & & 0.186 \\
\hline Positive (with DC) & $330(73.3)$ & $62(18.8)$ & $189(57.3)$ & $79(23.9)$ & \\
\hline Negative (without DC) & $120(26.7)$ & $19(15.8)$ & $80(66.7)$ & $21(17.5)$ & \\
\hline Co-morbidities & & & & & 0.553 \\
\hline
\end{tabular}


(Table 4) contd.....

\begin{tabular}{|c|c|c|c|c|c|}
\hline \multirow{4}{*}{ Variable } & \multirow{4}{*}{$\begin{array}{c}\text { Total Sample }(\mathbf{N}=450) \\
\text { N (\%) }\end{array}$} & \multicolumn{3}{|c|}{ QUS Score, $\mathbf{N}(\%)$} & \multirow{4}{*}{$P$ value } \\
\hline & & \multirow{3}{*}{\begin{tabular}{|c|} 
Normal BMD \\
Normal \\
$\mathbf{8 1}(\mathbf{1 8 . 0} \%)$ \\
\end{tabular}} & \multicolumn{2}{|c|}{ LBMD } & \\
\hline & & & Osteopenia & Osteoporosis & \\
\hline & & & $269(59.8 \%)$ & $100(22.2 \%)$ & \\
\hline Positive (with Co-morbidities) & $426(94.7)$ & $75(17.6)$ & $257(60.3)$ & $94(22.1)$ & \\
\hline Negative (without Co-morbidities) & $24(5.3)$ & $6(25.0)$ & $12(50.0)$ & $6(25.0)$ & \\
\hline Insulin use & & & & & 0.369 \\
\hline With insulin & $67(14.9)$ & $16(23.9)$ & $36(53.7)$ & $15(22.4)$ & \\
\hline Without insulin & $383(85.1)$ & $65(17.0)$ & $233(60.8)$ & $85(22.2)$ & \\
\hline Glycaemic control & & & & & $0.020 *$ \\
\hline Good HbA1c $(<6.5)$ & $107(23.8)$ & $28(26.2)$ & $62(57.9)$ & $17(15.9)$ & \\
\hline Poor HbA1c $(\geq 6.5)$ & $343(76.2)$ & $53(15.5)$ & $207(60.3)$ & $83(24.2)$ & \\
\hline
\end{tabular}

Chi-square test, $* P<0.05$.

QUS, quantitative ultrasound; BMD, bone mineral density; LBMD, low bone mineral density.

Moreover, significant negative correlations were found between T-score and QUS parameters with glycaemic control (HbA1c) and duration of diabetes, as well as Systolic Blood Pressure (SBP) $(P<0.05)$. In addition, insignificant correlations were found between T-score and QUS parameters with both lipid and blood pressure profiles $(P>0.05)$, as shown in Table 5.

Table 5. Correlation between $\mathrm{T}$-score and quantitative ultrasound scan parameter value with clinical data $(\mathrm{N}=450)$.

\begin{tabular}{|c|c|c|c|c|c|}
\hline Variables & T-score & BUA & SOS & SI & eBMD \\
\hline Diabetes duration, $r_{s}$ & $-0.114^{*}$ & -0.082 & $-0.122 * *$ & $-0.097^{*}$ & $-0.108^{*}$ \\
\hline Glycaemic control, $r_{s}$ & $-0.190 * *$ & $-0.152 * *$ & $-0.193 * *$ & $-0.169 * *$ & $-0.185^{* *}$ \\
\hline $\mathrm{TC}, r$ & 0.083 & 0.070 & 0.088 & 0.079 & 0.084 \\
\hline HDLC, $r_{s}$ & -0.020 & -0.045 & 0.002 & -0.034 & -0.025 \\
\hline LDLC, $r$ & -0.001 & -0.004 & 0.002 & -0.003 & -0.001 \\
\hline $\mathrm{TG}, r_{s}$ & -0.023 & -0.006 & -0.035 & -0.010 & -0.016 \\
\hline $\mathrm{SBP}, r_{s}$ & -0.087 & $-0.095 *$ & -0.073 & $-0.099 *$ & $-0.092 *$ \\
\hline $\mathrm{DBP}, r_{s}$ & 0.041 & -0.003 & 0.062 & 0.015 & 0.031 \\
\hline
\end{tabular}

$r$, Pearson correlation; $r_{s}$, Spearman correlation; BUA, broadband ultrasound attenuation; SOS, speed of the sound; SI, stiffness index; eBMD, estimated bone mineral density; BMI, body mass index; TC, total cholesterol; HDLC, high density lipoprotein cholesterol; LDLC, low density lipoprotein cholesterol, TG, triglyceride, SBP, systolic blood pressure; DBP, diastolic blood pressure; ${ }^{*} P<0.05, * * P<0.01$.

\section{DISCUSSION}

Diabetes mellitus and osteoporosis are two clinical syndromes with a great impact on public health that affect a large proportion of people around the world. The clinical relevance of osteoporosis related to T2DM is less acknowledged and, to date, no clear findings have been reached due to the inconsistent findings among researchers; they have reported lower, equal and greater bone mass in T2DM [48]. To the best of the researchers' knowledge, this was the first extensive field study using calcaneal QUS to determine and identify the prevalence of osteoporosis and osteopenia in Malaysian diabetic type 2 patients in Penang state.

\subsection{Prevalence of Osteoporotic Conditions}

This study showed that T2DM patients had a high prevalence of osteopenia $(59.80 \%)$ and osteoporosis $(22.20 \%)$. Comparable results were found in other studies using QUS [49] and DXA [50]. However, the prevalence of osteoporosis in the present study was lower than other studies of Asian populations [51, 52] and other western country [53]. On the other hand, the overall prevalence of osteoporosis in this study was higher than those reported in several other studies in different countries, using either DXA [54, 55] or QUS [56, 10]. Therefore, it appears that osteoporosis in Malaysian T2DM patients is underdiagnosed and overlooked until now.

\subsection{Quantitative Ultrasound Parameters Measurements}

The QUS parameters demonstrated significant inverse correlations with age. Moreover, the results showed an obvious decrease in all QUS parameters (BUA, SOS, eBMD, SI) with age and the average values for men were higher than those for women. Similar findings were seen by other researchers using the QUS in the general population [57, 58]. Moreover, similar evidence from previous cross-sectional studies in European [59, 60] and Asian populations [61, 
21] using the QUS measurement have reported that QUS parameters start to decline from the age of 40-45 years and continue to decrease rapidly with age.

The peak values for the QUS parameters in the present study occurred in the age group younger than 45 years, which are consistent with other studies [62, 63]. In agreement with previous reports, the decline of BMD in Asian men is slower than in women, especially after the age of 50 years [64, 65]. Moreover, osteoporosis was more common among women compared to men using calcaneal QUS measurements [66, 10]. Furthermore, the decline in women within this study was more prominent after the age of 55 years. The differences in age at peak bone mass and the beginning of bone mass reduction could be partly explained by the characteristics of bone (skeletal sites), as well as, the measurement methods used [67].

The prevalence of osteoporosis and osteopenia was higher in females than males. It was generally assumed that osteoporosis is less common in men than women. This is because men has shown greater BMD at all areal sites and the average percent loss in BMD for men was much lower than the loss for women at all sites [68, 69]. Other studies showed higher or no difference in BMD in T2DM men when compared with healthy controls [70 - 72]. However, many studies revealed lower BMD among men T2DM patients when compared to healthy controls [73, 74], as well as, higher prevalence of osteoporosis in diabetic men after adjustment for age and BMI [75]. It was estimated that each year, there were approximately 1\% BMD losses in men with diabetes [76] and the risk of fall related fracture was increased due to the decline in muscular strength and neuromuscular function [74]. Thus, the problem of osteoporosis in men has been overlooked.

\subsection{Socio-Demographic Data and Bone Health Status}

The QUS parameters demonstrated significant inverse correlations with menopausal duration and positive correlations with BMI and WHR. These results are largely consistent with those found in Caucasian and Asian populations using the QUS method [77, 78]. Similar findings were reported in diabetes patients in a Persian study which showed that T-score using DXA was inversely related to the duration of menopause [79]. Another study showed that the duration of menopause, as well as, the age and duration of diabetes, were amongst risk factors for decreasing BMD in diabetic patients [80]. It is obviously known that osteoporosis is a problem related to age and hormonal changes in women, suggesting a hormonal influence on BMD [81]. Moreover, similar findings were reported in postmenopausal women with T2DM using QUS [82]. This might be due to the fact that there is an increase in bone resorption relative to formation as a consequence of aging, which is an important cause of osteoporosis in the elderly [12].

The high prevalence of osteoporosis in Malaysian postmenopausal women is probably related to their short, small skeletal frame and the mainly sedentary lifestyles [83, 33]. However, the osteoporosis prevalence in postmenopausal women with T2DM in the present study was lower than those reported in other studies of postmenopausal T2DM patients using DXA [84, 85] or QUS for non-diabetic postmenopausal women [86, 87]. On the other hand, the current study results showed a higher prevalence of osteoporosis than another study using DXA in T2DM Iranian postmenopausal women [88], or using QUS among Vietnamese, Korean and Indian postmenopausal women [89 - 91]. The reason behind the differences in the prevalence of low bone mass reported in different countries can be due to the differences in the individual's lifestyles variables, the method used for measurements and the study design. Additionally, in this study, QUS parameters and the T-score positively correlated with BMI and WHR. Similar findings were reported in other studies, as QUS parameters were inversely correlated with age and positively correlated with weight and BMI; however, no correlation was found with height [92, 93].

\subsection{Clinical Related Data and Bone Health Status}

In the present study, the result revealed that more than three quarters of T2DM patients presenting with osteoporosis $(83 \%)$ had poor glycaemic control and that an increased diabetic duration of more than 10 years led to a high prevalence of osteopenia and osteoporosis. Moreover, the T-scores and QUS parameters demonstrated significant inverse correlations with glycaemic control (HbA1c) and diabetes duration. Therefore, it is important to maintain a good glycaemic control, as this will lead to slower bone loss in T2DM patients.

Several studies confirm the finding of the current study that glycaemic control is considered to be a confounding factor that affects BMD. In these studies, BMD was more severely decreased in the poorly glycaemic controlled T2DM patients; thus, the bone health status could be improved by maintaining good glycaemic control [94, 95]. On the other hand, other studies have shown that higher BMD was associated with poor glyceamic control in T2DM patients [96, 97] and could be explained by their hyperinsulinaemia and insulin resistance [98,99]. Several studies indicated that insulin 
has shown a potential anabolic effect on skeleton tissue [100, 101], as well as, it is responsible for increased BMD in T2DM [102]. Thus, elevated BMD in T2DM, at least in the early phase, hallmarked by increased insulin level [103], then later when the pancreases cannot be able to secrete enough insulin to overcome the increased insulin resistance that results in periods of hyperinsulinemia [104].

On the other hand, some studies have shown that there was no relationship between T-score and HbA1c [105, 106], which was in accordance with the results from a meta-analysis performed in diabetic patients [107]. Thus, it is possible that the effects of hyperglycaemia and poor glycaemic control are not associated with increased bone resorption and bone turnover in T2DM and that BMD is not altered in T2DM [108]. Meanwhile, fractures are more commonly reported in T2DM patients with chronic diabetic complications $[109,110]$; therefore, the HbA1c in T2DM patients is still a significance factor, although some previous researchers have shown no direct association between that HbA1c and BMD.

In this study, the results showed that increased diabetic duration (more than 10 years) leads to a high prevalence of osteopenia and osteoporosis. In addition, there was a negative correlation between T-score and QUS parameters with diabetes duration. These result consistent with the previous reported research [106]. Similar findings suggested that age and the duration of diabetes were additional risk factors for developing osteoporotic conditions, as BMD was inversely correlated with age and the duration of diabetes [111, 112]. In contrast, other study did not find any significant relationship between the duration of diabetes and BMD [105]. This inconsistency may be due to the non-randomised control study with small sample sizes, different durations of diabetes and different sites of measurements.

This study only targeted outpatients with Type 2 Diabetes Mellitus in HPP, who may not represent all Malaysian diabetic patients. However, the sample size was large enough to represent all diabetic patients managed in the outpatient clinic of HPP. The convenient sampling and cross-sectional design study further limits the generalisation of the findings to the entire Malaysian population. Moreover, unequal numbers of ethnic, age, and gender groups may impact the final results if compared with a randomised control study or longitudinal study.

\section{CONCLUSION}

This study found that diabetic patients had a high risk of abnormal BMD. As there is evidence that osteoporosis is a preventable disease, the screening, identification and prevention of potential risk factors for osteoporosis in T2DM patients is crucial. It would be appropriate to offer an educational program to individuals about healthy lifestyles that could potentially prevent or control osteoporosis, like engaging in physical activity, maintaining a healthy body mass, minimising the use of tobacco and alcohol, and ingesting appropriate nutrition (adequate dietary intake of calcium and vitamin D). This action may contribute to healthy bones and play a role in the practical prevention of osteoporosis in Asian population.

\section{ETHICS APPROVAL AND CONSENT TO PARTICIPATE}

This study was approved by the Clinical Research Centre (CRC) of Hospital Palua Pinang and the Medical Research Ethics Committee (MREC) of the Ministry of Health, Malaysia (NMRR-11-28-8209).

\section{HUMAN AND ANIMAL RIGHTS}

No animals were used in this research. The study involved quantitative ultrasound measurement from human subjects after obtaining written informed consent. It was conducted in compliance with the principles laid in declaration of Helsinki in 1975 and revised in 1983.

\section{CONSENT FOR PUBLICATION}

An informed consent was obtained from the patients when they were enrolled.

\section{CONFLICT OF INTEREST}

The authors declare no conflict of interest, financial or otherwise.

\section{ACKNOWLEDGEMENTS}

This study is supported by Research University Postgraduate Research Grant Scheme (RU-PRGS) (1001/PFARMASI) from University Sains Malaysia. Moreover, the corresponding author wishes to acknowledge and 
extend gratitude for Universiti Science Malaysia (USM) for its support in undertaking this work through the USM fellowship program.

\section{REFERENCES}

[1] Cooper C. Epidemiology of osteoporosis. Osteoporos Int 1999; 9(Suppl. 2): S2-8. [http://dx.doi.org/10.1007/PL00004156] [PMID: 10525719]

[2] Parsons LC. Osteoporosis: Incidence, prevention, and treatment of the silent killer. Nurs Clin North Am 2005; 40(1): 119-33. [http://dx.doi.org/10.1016/j.cnur.2004.09.001] [PMID: 15733951]

[3] Blotman F, Cortet B, Hilliquin P, et al. Characterisation of patients with postmenopausal osteoporosis in French primary healthcare. Drugs Aging 2007; 24(7): 603-14. [http://dx.doi.org/10.2165/00002512-200724070-00007] [PMID: 17658910]

[4] Khaw KT, Reeve J, Luben R, et al. Prediction of total and hip fracture risk in men and women by quantitative ultrasound of the calcaneus: EPIC-Norfolk prospective population study. Lancet 2004; 363(9404): 197-202. [http://dx.doi.org/10.1016/S0140-6736(03)15325-1] [PMID: 14738792]

[5] Cauley JA, Thompson DE, Ensrud KC, Scott JC, Black D. Risk of mortality following clinical fractures. Osteoporos Int 2000; 11(7): 556-61. [http://dx.doi.org/10.1007/s001980070075] [PMID: 11069188]

[6] Melton LJ III. Adverse outcomes of osteoporotic fractures in the general population. J Bone Miner Res 2003; $18(6)$ : 1139-41. [http://dx.doi.org/10.1359/jbmr.2003.18.6.1139] [PMID: 12817771]

[7] Cotté FE, Cortet B, Lafuma A, et al. A model of the public health impact of improved treatment persistence in post-menopausal osteoporosis in France. Joint Bone Spine 2008; 75(2): 201-8. [http://dx.doi.org/10.1016/j.jbspin.2007.06.004] [PMID: 17988921]

[8] Salkeld G, Cameron ID, Cumming RG, et al. Quality of life related to fear of falling and hip fracture in older women: A time trade off study. BMJ 2000; 320(7231): 341-6.

[http://dx.doi.org/10.1136/bmj.320.7231.341] [PMID: 10657327]

[9] Caliri A, De Filippis L, Bagnato GL, Bagnato GF. Osteoporotic fractures: Mortality and quality of life. Panminerva Med 2007; $49(1)$ : 21-7. [PMID: 17468730]

[10] Maggi S, Noale M, Giannini S, et al. Quantitative heel ultrasound in a population-based study in Italy and its relationship with fracture history: The ESOPO study. Osteoporos Int 2006; 17(2): 237-44. [http://dx.doi.org/10.1007/s00198-005-1985-2] [PMID: 16142503]

[11] Becker DJ, Kilgore ML, Morrisey MA. The societal burden of osteoporosis. Curr Rheumatol Rep 2010; $12(3)$ : $186-91$. [http://dx.doi.org/10.1007/s11926-010-0097-y] [PMID: 20425518]

[12] Lane NE. Epidemiology, etiology, and diagnosis of osteoporosis. Am J Obstet Gynecol 2006; 194(2)(Suppl.): S3-S11. [http://dx.doi.org/10.1016/j.ajog.2005.08.047] [PMID: 16448873]

[13] Kin K, Kushida K, Yamazaki K, Okamoto S, Inoue T. Bone mineral density of the spine in normal Japanese subjects using dual-energy X-ray absorptiometry: Effect of obesity and menopausal status. Calcif Tissue Int 1991; 49(2): 101-6. [http://dx.doi.org/10.1007/BF02565129] [PMID: 1913287]

[14] Lau EM, Cooper C. The epidemiology of osteoporosis. The oriental perspective in a world context. Clin Orthop Relat Res 1996; (323): 65-74. [http://dx.doi.org/10.1097/00003086-199602000-00009] [PMID: 8625608]

[15] Tan S, Ji L, Tsai J, et al. Greater osteoporosis educational outreach is desirable among Chinese immigrants in Chinatown, Chicago. Osteoporos Int 2009; 20(9): 1517-22. [http://dx.doi.org/10.1007/s00198-008-0828-3] [PMID: 19148565]

[16] Mithal A, Dhingra V, Lau E. The asian Audit: Epidemiology, costs and burden of osteoporosis in Asia 2009.http://www.iofbonehealth.org/ sites/default/files/

[17] Marín F, González-Macías J, Díez-Pérez A, Palma S, Delgado-Rodríguez M. Relationship between bone quantitative ultrasound and fractures: A meta-analysis. J Bone Miner Res 2006; 21(7): 1126-35. [http://dx.doi.org/10.1359/jbmr.060417] [PMID: 16813534]

[18] Miller PD, Siris ES, Barrett-Connor E, et al. Prediction of fracture risk in postmenopausal white women with peripheral bone densitometry: Evidence from the National Osteoporosis Risk Assessment. J Bone Miner Res 2002; 17(12): 2222-30. [http://dx.doi.org/10.1359/jbmr.2002.17.12.2222] [PMID: 12469916]

[19] Guglielmi G, de Terlizzi F. Quantitative ultrasond in the assessment of osteoporosis. Eur J Radiol 2009; 71(3): $425-31$. [http://dx.doi.org/10.1016/j.ejrad.2008.04.060] [PMID: 19651483]

[20] Rhee Y, Lee J, Jung JY, et al. Modifications of T-scores by quantitative ultrasonography for the diagnosis of osteoporosis in koreans. J Korean Med Sci 2009; 24(2): 232-6. [http://dx.doi.org/10.3346/jkms.2009.24.2.232] [PMID: 19399263]

[21] Lin JD, Chen JF, Chang HY, Ho C. Evaluation of bone mineral density by quantitative ultrasound of bone in 16,862 subjects during routine health examination. Br J Radiol 2001; 74(883): 602-6. 
[http://dx.doi.org/10.1259/bjr.74.883.740602] [PMID: 11509395]

[22] Sakata S, Barkmann R, Lochmüller EM, Heller M, Glüer CC. Assessing bone status beyond BMD: Evaluation of bone geometry and porosity by quantitative ultrasound of human finger phalanges. J Bone Miner Res 2004; 19(6): 924-30. [http://dx.doi.org/10.1359/JBMR.040131] [PMID: 15125791]

[23] Albanese CV, Cepollaro C, de Terlizzi F, Brandi ML, Passariello R. Performance of five phalangeal QUS parameters in the evaluation of gonadal-status, age and vertebral fracture risk compared with DXA. Ultrasound Med Biol 2009; 35(4): 537-44. [http://dx.doi.org/10.1016/j.ultrasmedbio.2008.09.027] [PMID: 19097682]

[24] Omodei U, Benussi C, Ramazzotto F, Feller M, Gambacciani M. Risk identification of osteoporosis in postmenopausal women by a simple algorithm based on ultrasound densitometry and body mass index. J Clin Densitom 2008; 11(3): 412-6. [http://dx.doi.org/10.1016/j.jocd.2008.01.003] [PMID: 18375162]

[25] Jenkins DK. Assessing Bone Mass with the QUS-2 Calcaneal Ultrasonometer. Transplantation 2001; 21: 1-11.

[26] Krieg MA, Barkmann R, Gonnelli S, et al. Quantitative ultrasound in the management of osteoporosis: The 2007 ISCD Official Positions. J Clin Densitom 2008; 11(1): 163-87. [http://dx.doi.org/10.1016/j.jocd.2007.12.011] [PMID: 18442758]

[27] Luft FC. Does diabetes really cause bone disease? J Mol Med (Berl) 2012; 90(11): 1233-5. [http://dx.doi.org/10.1007/s00109-012-0959-z] [PMID: 23052482]

[28] Isidro ML, Ruano B. Bone disease in diabetes. Curr Diabetes Rev 2010; 6(3): 144-55. [http://dx.doi.org/10.2174/157339910791162970] [PMID: 20380629]

[29] Adami S. Bone health in diabetes: Considerations for clinical management. Curr Med Res Opin 2009; 25(5): 1057-72. [http://dx.doi.org/10.1185/03007990902801147] [PMID: 19292601]

[30] Rakic V, Davis WA, Chubb SA, Islam FM, Prince RL, Davis TM. Bone mineral density and its determinants in diabetes: The fremantle diabetes study. Diabetologia 2006; 49(5): 863-71.

[http://dx.doi.org/10.1007/s00125-006-0154-2] [PMID: 16518589]

[31] Janghorbani M, Van Dam RM, Willett WC, Hu FB. Systematic review of type 1 and type 2 diabetes mellitus and risk of fracture. Am J Epidemiol 2007; 166(5): 495-505. [http://dx.doi.org/10.1093/aje/kwm106] [PMID: 17575306]

[32] Zanariah H, Chandran LR, Wan Mohamad WB, et al. Prevalence of diabetes mellitus in Malaysia in 2006-results of the 3rd National Health and Morbidity Survey (NHMS III). Diabetes Res Clin Pract 2008; 79: 21-9. [http://dx.doi.org/10.1016/S0168-8227(08)70699-5]

[33] Lim PS, Ong FB, Adeeb N, et al. Bone health in urban midlife Malaysian women: Risk factors and prevention. Osteoporos Int 2005; 16(12): 2069-79.

[http://dx.doi.org/10.1007/s00198-005-2003-4] [PMID: 16234999]

[34] Cochran WG. Sampling techniques. New York: John Wiley \& Sons 1977.

[35] Ali SM, Jusoff K. Barriers to optimal control of type 2 diabetes in malaysian malay patients. Glob J Health Sci 2009; 1: 106-18. [http://dx.doi.org/10.5539/gjhs.v1n2p106]

[36] Glüer CC, Wu CY, Jergas M, Goldstein SA, Genant HK. Three quantitative ultrasound parameters reflect bone structure. Calcif Tissue Int 1994; 55(1): 46-52. [http://dx.doi.org/10.1007/BF00310168] [PMID: 7922789]

[37] Young H, Howey S, Purdie DW. Broadband ultrasound attenuation compared with dual-energy X-ray absorptiometry in screening for postmenopausal low bone density. Osteoporos Int 1993; 3(3): 160-4. [http://dx.doi.org/10.1007/BF01623278] [PMID: 8481593]

[38] Bauer DC, Glüer CC, Cauley JA, et al. Broadband ultrasound attenuation predicts fractures strongly and independently of densitometry in older women. A prospective study. Arch Intern Med 1997; 157(6): 629-34. [http://dx.doi.org/10.1001/archinte.1997.00440270067006] [PMID: 9080917]

[39] Thompson PW, Taylor J, Oliver R, Fisher A. Quantitative ultrasound (QUS) of the heel predicts wrist and osteoporosis-related fractures in women age 45-75 years. J Clin Densitom 1998; 1(3): 219-25. [http://dx.doi.org/10.1385/JCD:1:3:219] [PMID: 15304892]

[40] Canhão H, Lucas R, Fonseca JE, et al. Factors influencing calcaneus quantitative ultrasound measurements in an urban population. Clin Exp Rheumatol 2008; 26(1): 67-72. [PMID: 18328149]

[41] Frost ML, Blake GM, Fogelman I. Can the WHO criteria for diagnosing osteoporosis be applied to calcaneal quantitative ultrasound? Osteoporos Int 2000; 11(4): 321-30. [http://dx.doi.org/10.1007/s001980070121] [PMID: 10928222]

[42] Faulkner KG, McClung MR, Coleman LJ, Kingston-Sandahl E. Quantitative ultrasound of the heel: Correlation with densitometric measurements at different skeletal sites. Osteoporos Int 1994; 4(1): $42-7$. [http://dx.doi.org/10.1007/BF02352260] [PMID: 8148571] 
[43] Hans D, Dargent-Molina P, Schott AM, et al. Ultrasonographic heel measurements to predict hip fracture in elderly women: The EPIDOS prospective study. Lancet 1996; 348(9026): 511-4. [http://dx.doi.org/10.1016/S0140-6736(95)11456-4] [PMID: 8757153]

[44] Kanis JA, McCloskey EV, Johansson H, Oden A, Melton LJ III, Khaltaev N. A reference standard for the description of osteoporosis. Bone 2008; 42(3): 467-75. [http://dx.doi.org/10.1016/j.bone.2007.11.001] [PMID: 18180210]

[45] Rozental TD, Shah J, Chacko AT, Zurakowski D. Prevalence and predictors of osteoporosis risk in orthopaedic patients. Clin Orthop Relat Res 2010; 468(7): 1765-72.

[http://dx.doi.org/10.1007/s11999-009-1162-6] [PMID: 19911243]

[46] Field AP. Discovering statistics using SPSS. London: SAGE publications Ltd 2009.

[47] Sekaran U. Research methods for business: A skill building approach. India: John Wiley \& Sons 2007.

[48] Abdulameer SA, Sulaiman SA, Hassali MA, Subramaniam K, Sahib MN. Osteoporosis and type 2 diabetes mellitus: What do we know, and what we can do? Patient Prefer Adherence 2012; 6: 435-48.

[http://dx.doi.org/10.2147/PPA.S32745] [PMID: 22791981]

[49] de Luis Román DA, Aller R, Perez Castrillon JL, et al. Effects of dietary intake and life style on bone density in patients with diabetes mellitus type 2. Ann Nutr Metab 2004; 48(3): 141-5. [http://dx.doi.org/10.1159/000078376] [PMID: 15133318]

[50] El-Maouche D, Xu X, Cofrancesco J Jr, Dobs AS, Brown TT. Prevalence of low bone mineral density in a low-income inner-city population. J Bone Miner Res 2011; 26(2): 388-96. [http://dx.doi.org/10.1002/jbmr.221] [PMID: 20721937]

[51] Chen HL, Deng LL, Li JF. Prevalence of osteoporosis and its associated factors among older men with type 2 diabetes. Int J Endocrinol 2013; 2013: 285729.

[http://dx.doi.org/10.1155/2013/285729] [PMID: 23401682]

[52] Wu XP, Liao EY, Zhang H, et al. Determination of age-specific bone mineral density and comparison of diagnosis and prevalence of primary osteoporosis in Chinese women based on both Chinese and World Health Organization criteria. J Bone Miner Metab 2004; 22 (4): $382-91$. [http://dx.doi.org/10.1007/s00774-004-0499-x] [PMID: 15221499]

[53] Bulló M, Garcia-Aloy M, Basora J, Covas MI, Salas-Salvado J. Bone quantitative ultrasound measurements in relation to the metabolic syndrome and type 2 diabetes mellitus in a cohort of elderly subjects at high risk of cardiovascular disease from the PREDIMED study. J Nutr Health Aging 2011; 15(10): 939-44. [http://dx.doi.org/10.1007/s12603-011-0046-0] [PMID: 22159786]

[54] Binkley N, Kiebzak GM, Lewiecki EM, et al. Recalculation of the NHANES database SD improves T-score agreement and reduces osteoporosis prevalence. J Bone Miner Res 2005; 20(2): 195-201. [http://dx.doi.org/10.1359/JBMR.041115] [PMID: 15647812]

[55] Boyanov M, Popivanov P. Prevalence of low forearm bone density in a Bulgarian female referral population. Osteoporos Int 2002; 13(4): 288-95.

[http://dx.doi.org/10.1007/s001980200028] [PMID: 12030543]

[56] Biino G, Casula L, de Terlizzi F, et al. Epidemiology of osteoporosis in an isolated Sardinian population by using quantitative ultrasound. Am J Epidemiol 2011; 174(4): 432-9. [http://dx.doi.org/10.1093/aje/kwr106] [PMID: 21709133]

[57] Magkos F, Manios Y, Babaroutsi E, Sidossis LS. Quantitative ultrasound calcaneus measurements: Normative data for the Greek population. Osteoporos Int 2005; 16(3): 280-8. [http://dx.doi.org/10.1007/s00198-004-1670-x] [PMID: 15241583]

[58] Sosa M, Saavedra P, Muñoz-Torres M, et al. Quantitative ultrasound calcaneus measurements: Normative data and precision in the Spanish population. Osteoporos Int 2002; 13(6): 487-92. [http://dx.doi.org/10.1007/s001980200059] [PMID: 12107663]

[59] Frost ML, Blake GM, Fogelman I. Quantitative ultrasound and bone mineral density are equally strongly associated with risk factors for osteoporosis. J Bone Miner Res 2001; 16(2): 406-16. [http://dx.doi.org/10.1359/jbmr.2001.16.2.406] [PMID: 11204441]

[60] Landin-Wilhelmsen K, Johansson S, Rosengren A, et al. Calcaneal ultrasound measurements are determined by age and physical activity. Studies in two Swedish random population samples. J Intern Med 2000; 247(2): 269-78. [http://dx.doi.org/10.1046/j.1365-2796.2000.00642.x] [PMID: 10692091]

[61] Kim CH, Kim YI, Choi CS, et al. Prevalence and risk factors of low quantitative ultrasound values of calcaneus in Korean elderly women. Ultrasound Med Biol 2000; 26(1): 35-40. [http://dx.doi.org/10.1016/S0301-5629(99)00126-X] [PMID: 10687790]

[62] Kung AW, Tang GW, Luk KD, Chu LW. Evaluation of a new calcaneal quantitative ultrasound system and determination of normative ultrasound values in Southern Chinese women. Osteoporos Int 1999; 9(4): 312-7. [http://dx.doi.org/10.1007/s001980050153] [PMID: 10550448] 
[63] Von Stetten E, Wilson K, Steiger P, Stein J. Initial evaluation of a waterless calcaneal ultrasound system: The Sahara clinical bone sonometer. Osteoporos Int 1996; 6: 190-6. [http://dx.doi.org/10.1007/BF02500298]

[64] Sugimoto T, Tsutsumi M, Fujii Y, et al. Comparison of bone mineral content among Japanese, Koreans, and Taiwanese assessed by dualphoton absorptiometry. J Bone Miner Res 1992; 7(2): 153-9. [http://dx.doi.org/10.1002/jbmr.5650070206] [PMID: 1570760]

[65] Tsai KS, Huang KM, Chieng PU, Su CT. Bone mineral density of normal Chinese women in Taiwan. Calcif Tissue Int 1991; $48:$ 161-6. [http://dx.doi.org/10.1007/BF02570550]

[66] Arslantas D, Metintas S, Unsal A, Isikli B, Kalyoncu C, Arslantas A. Prevalence of osteoporosis in middle Anatolian population using calcaneal ultrasonography method. Maturitas 2008; 59(3): 234-41. [http://dx.doi.org/10.1016/j.maturitas.2008.01.007] [PMID: 18343057]

[67] Cheng S, Fan B, Wang L, et al. Factors affecting broadband ultrasound attenuation results of the calcaneus using a gel-coupled quantitative ultrasound scanning system. Osteoporos Int 1999; 10(6): 495-504. [http://dx.doi.org/10.1007/s001980050260] [PMID: 10663351]

[68] Bailey DA, Martin AD, McKay HA, Whiting S, Mirwald R. Calcium accretion in girls and boys during puberty: A longitudinal analysis. J Bone Miner Res 2000; 15(11): 2245-50. [http://dx.doi.org/10.1359/jbmr.2000.15.11.2245] [PMID: 11092406]

[69] Hannan MT, Felson DT, Dawson-Hughes B, et al. Risk factors for longitudinal bone loss in elderly men and women: The framingham osteoporosis study. J Bone Miner Res 2000; 15(4): 710-20. [http://dx.doi.org/10.1359/jbmr.2000.15.4.710] [PMID: 10780863]

[70] Lunt M, Masaryk P, Scheidt-Nave C, et al. The effects of lifestyle, dietary dairy intake and diabetes on bone density and vertebral deformity prevalence: The EVOS study. Osteoporos Int 2001; 12(8): 688-98. [http://dx.doi.org/10.1007/s001980170069] [PMID: 11580083]

[71] Schwartz AV, Sellmeyer DE, Strotmeyer ES, et al. Diabetes and bone loss at the hip in older black and white adults. J Bone Miner Res 2005; 20(4): 596-603. [http://dx.doi.org/10.1359/JBMR.041219] [PMID: 15765178]

[72] Strotmeyer ES, Cauley JA, Schwartz AV, et al. Diabetes is associated independently of body composition with BMD and bone volume in older white and black men and women: The health, aging, and body composition study. J Bone Miner Res 2004; 19 (7): 1084-91. [http://dx.doi.org/10.1359/JBMR.040311] [PMID: 15176990]

[73] Gregorio F, Cristallini S, Santeusanio F, Filipponi P, Fumelli P. Osteopenia associated with non-insulin-dependent diabetes mellitus: What are the causes? Diabetes Res Clin Pract 1994; 23(1): 43-54. [http://dx.doi.org/10.1016/0168-8227(94)90126-0] [PMID: 8013262]

[74] Petit MA, Paudel ML, Taylor BC, et al. Bone mass and strength in older men with type 2 diabetes: The osteoporotic fractures in men study. J Bone Miner Res 2010; 25(2): 285-91. [http://dx.doi.org/10.1359/jbmr.090725] [PMID: 19594301]

[75] Yaturu S, Humphrey S, Landry C, Jain SK. Decreased bone mineral density in men with metabolic syndrome alone and with type 2 diabetes. Med Sci Monit 2009; 15(1): CR5-9. [PMID: 19114969]

[76] Issa C, Zantout MS, Azar ST. Osteoporosis in men with diabetes mellitus. J Osteoporos 2011; 2011: 651867. [http://dx.doi.org/10.4061/2011/651867] [PMID: 21772974]

[77] Heldan de Moura Castro C, Medeiros Pinheiro M, Lúcia Szejnfeld V. Quantitative ultrasound of the calcaneus in Brazilian Caucasian women: Normative data are similar to the manufacturer's normal range. Osteoporos Int 2000; 11(11): 923-8. [http://dx.doi.org/10.1007/s001980070030] [PMID: 11193244]

[78] Yamaguchi J, Truman G, Cameron ID. Lifestyle factors affecting bone ultrasonometry of the calcaneus in Japanese women. Calcif Tissue Int 2000; 66(1): 43-6. [http://dx.doi.org/10.1007/s002230050008] [PMID: 10602843]

[79] Sharifi F, Ahmadimoghadam N, Mousavinasab N. The relationship between type 2 diabetes mellitus and bone density in postmenopausal women. Int J Endocrinol Metab 2006; 4: 117-22.

[80] Kwon DJ, Kim JH, Chung KW, et al. Bone mineral density of the spine using dual energy X-ray absorptiometry in patients with non-insulindependent diabetes mellitus. J Obstet Gynaecol Res 1996; 22(2): 157-62. [http://dx.doi.org/10.1111/j.1447-0756.1996.tb00959.x] [PMID: 8697346]

[81] Rizzoli R, Bonjour JP, Ferrari SL. Osteoporosis, genetics and hormones. J Mol Endocrinol 2001; 26(2): 79-94. [http://dx.doi.org/10.1677/jme.0.0260079] [PMID: 11241160]

[82] Hosoda H, Fukui M, Nakayama I, et al. Bone mass and bone resorption in postmenopausal women with type 2 diabetes mellitus. Metabolism 2008; 57(7): 940-5.

[http://dx.doi.org/10.1016/j.metabol.2008.02.009] [PMID: 18555835] 
[83] Hamid AK. Orthopaedic problems in the elderly. Med J Malaysia 1997; 52(3): 226-30. [PMID: 10968090]

[84] Viégas M, Costa C, Lopes A, Griz L, Medeiro MA, Bandeira F. Prevalence of osteoporosis and vertebral fractures in postmenopausal women with type 2 diabetes mellitus and their relationship with duration of the disease and chronic complications. J Diabetes Complications 2011 ; 25(4): 216-21. [http://dx.doi.org/10.1016/j.jdiacomp.2011.02.004] [PMID: 21458300]

[85] Zhou Y, Li Y, Zhang D, Wang J, Yang H. Prevalence and predictors of osteopenia and osteoporosis in postmenopausal Chinese women with type 2 diabetes. Diabetes Res Clin Pract 2010; 90(3): 261-9.

[http://dx.doi.org/10.1016/j.diabres.2010.09.013] [PMID: 20950884]

[86] Zaini WM, Md Ariff A. Bone mineral density assessment in pre- and postmenopausal women: Comparison between T-Scores by heel QUS and DXA in HRPZII. Med J Malaysia 2012; 67(5): 487-90. [PMID: 23770864]

[87] Wu XP, Liao EY, Luo XH, Dai RC, Zhang H, Peng J. Age-related variation in quantitative ultrasound at the tibia and prevalence of osteoporosis in native Chinese women. Br J Radiol 2003; 76(909): 605-10. [http://dx.doi.org/10.1259/bjr/56839904] [PMID: 14500274]

[88] Karimifar M, Pasha MA, Salari A, Zamani A, Salesi M, Motaghi P. Evaluation of bone loss in diabetic postmenopausal women. J Res Med Sci 2012; 17(11): 1033-8. [PMID: 23833577]

[89] Vu TT, Nguyen CK, Nguyen TL, et al. Determining the prevalence of osteoporosis and related factors using quantitative ultrasound in Vietnamese adult women. Am J Epidemiol 2005; 161(9): 824-30. [http://dx.doi.org/10.1093/aje/kwi105] [PMID: 15840614]

[90] Sharma S, Tandon VR, Mahajan A, Kour A, Kumar D. Preliminary screening of osteoporosis and osteopenia in urban women from Jammu using calcaneal QUS. Indian J Med Sci 2006; 60(5): 183-9.

[http://dx.doi.org/10.4103/0019-5359.25679] [PMID: 16733289]

[91] Yoon HK, Kim SW, Yim CH, et al. Metabolic characteristics and prevalence of osteoporosis among women in Tae-An area. J Korean Med Sci 2001; 16(3): 323-7.

[http://dx.doi.org/10.3346/jkms.2001.16.3.323] [PMID: 11410694]

[92] Durmaz B, Oncel S, Kirazli Y, et al. Quantitative calcaneal ultrasonometry: Normative data and age-related changes for stiffness index in the Turkish population. J Clin Densitom 2006; 9(2): 217-21. [http://dx.doi.org/10.1016/j.jocd.2006.02.002] [PMID: 16785084]

[93] Lee JH, Lee YH, Jung KH, et al. Bone mineral density in prediabetic men. Korean Diabetes J 2010; 34(5): $294-302$. [http://dx.doi.org/10.4093/kdj.2010.34.5.294] [PMID: 21076577]

[94] Majima T, Komatsu Y, Yamada T, et al. Decreased bone mineral density at the distal radius, but not at the lumbar spine or the femoral neck, in Japanese type 2 diabetic patients. Osteoporos Int 2005; 16(8): 907-13. [http://dx.doi.org/10.1007/s00198-004-1786-z] [PMID: 15558237]

[95] Xu L, Cheng M, Liu X, Shan P, Gao H. Bone mineral density and its related factors in elderly male Chinese patients with type 2 diabetes. Arch Med Res 2007; 38(2): 259-64.

[http://dx.doi.org/10.1016/j.arcmed.2006.10.003] [PMID: 17227738]

[96] Akin O, Göl K, Aktürk M, Erkaya S. Evaluation of bone turnover in postmenopausal patients with type 2 diabetes mellitus using biochemical markers and bone mineral density measurements. Gynecol Endocrinol 2003; 17(1): 19-29. [http://dx.doi.org/10.1080/gye.17.1.19.29] [PMID: 12724015]

[97] Sert M, Tetiker T, Kirim S, Soyupak S, Canataroğlu A, Koçak M. Type 2 diabetes mellitus and osteopenia: Is there an association? Acta Diabetol 2003; 40(2): 105-8.

[PMID: 12861410]

[98] Rebeca RG, Palas A. Cardiovascular disease, diabetes mellitus type 2 and osteoporosis. Rev Osteoporos Metab Miner 2010; 2: 47-54.

[99] Stolk RP, Van Daele PL, Pols HA, et al. Hyperinsulinemia and bone mineral density in an elderly population: The Rotterdam Study. Bone 1996; 18(6): 545-9. [http://dx.doi.org/10.1016/8756-3282(96)00079-8] [PMID: 8805995]

[100] Reid IR, Evans MC, Cooper GJ, Ames RW, Stapleton J. Circulating insulin levels are related to bone density in normal postmenopausal women. Am J Physiol 1993; 265(4 Pt 1): E655-9.

[PMID: 8238341]

[101] Thrailkill KM, Lumpkin CK Jr, Bunn RC, Kemp SF, Fowlkes JL. Is insulin an anabolic agent in bone? Dissecting the diabetic bone for clues. Am J Physiol Endocrinol Metab 2005; 289(5): E735-45. [http://dx.doi.org/10.1152/ajpendo.00159.2005] [PMID: 16215165]

[102] van Daele PL, Stolk RP, Burger H, et al. Bone density in non-insulin-dependent diabetes mellitus. The Rotterdam Study. Ann Intern Med 1995; 122(6): 409-14. [http://dx.doi.org/10.7326/0003-4819-122-6-199503150-00002] [PMID: 7856988] 
[103] Yki-Järvinen H. Pathogenesis of non-insulin-dependent diabetes mellitus. Lancet 1994; 343(8889): 91-5. [http://dx.doi.org/10.1016/S0140-6736(94)90821-4] [PMID: 7903784]

[104] Wilcox G. Insulin and insulin resistance. Clin Biochem Rev 2005; 26(2): 19-39. [PMID: 16278749]

[105] Bridges MJ, Moochhala SH, Barbour J, Kelly CA. Influence of diabetes on peripheral bone mineral density in men: A controlled study. Acta Diabetol 2005; 42(2): 82-6.

[http://dx.doi.org/10.1007/s00592-005-0183-1] [PMID: 15944841]

[106] Tao B, Liu JM, Zhao HY, et al. Differences between measurements of bone mineral densities by quantitative ultrasound and dual-energy Xray absorptiometry in type 2 diabetic postmenopausal women. J Clin Endocrinol Metab 2008; 93(5): 1670-5. [http://dx.doi.org/10.1210/jc.2007-1760] [PMID: 18319321]

[107] Vestergaard P. Discrepancies in bone mineral density and fracture risk in patients with type 1 and type 2 diabetes-a meta-analysis. Osteoporos Int 2007; 18(4): 427-44. [http://dx.doi.org/10.1007/s00198-006-0253-4] [PMID: 17068657]

[108] Cutrim DM, Pereira FA, de Paula FJ, Foss MC. Lack of relationship between glycemic control and bone mineral density in type 2 diabetes mellitus. Braz J Med Biol Res 2007; 40(2): 221-7. [http://dx.doi.org/10.1590/S0100-879X2007000200008] [PMID: 17273658]

[109] Bonds DE, Larson JC, Schwartz AV, et al. Risk of fracture in women with type 2 diabetes: The Women's Health Initiative Observational Study. J Clin Endocrinol Metab 2006; 91(9): 3404-10. [http://dx.doi.org/10.1210/jc.2006-0614] [PMID: 16804043]

[110] de Liefde II, van der Klift M, de Laet CE, van Daele PL, Hofman A, Pols HA. Bone mineral density and fracture risk in type-2 diabetes mellitus: The Rotterdam Study. Osteoporos Int 2005; 16(12): 1713-20. [http://dx.doi.org/10.1007/s00198-005-1909-1] [PMID: 15940395]

[111] Al-Zaabi K, Badr HE, Mahussain S, Mohammad M, Al-Nafisi N, Badr HES. Bone mass density in diabetic women: Is there a detrimental effect? ME-JAA 2008; 5: 12-7.

[112] Guven M, Colak R, Tutufl A, Bayram F, Kula M, Kelefltimur F. The evaluation of bone mineral density in male and postmenopausal female patients with type 2 diabetes mellitus. Turk J Endocrinol Metab 1999; 4: 169-72.

(C) 2018 Abdulameer et al.

This is an open access article distributed under the terms of the Creative Commons Attribution 4.0 International Public License (CC-BY 4.0), a copy of which is available at: (https:/creativecommons.org/licenses/by/4.0/legalcode). This license permits unrestricted use, distribution, and reproduction in any medium, provided the original author and source are credited. 